\title{
High-Dose Intravenous Hydroxocobalamin for Persistent Vasoplegic Syndrome after Cardiac Surgery
}

\author{
Mohamed Ben-Omran, MD ${ }^{1 *}$, Ellen Huang, PharmD², Vijay S. Patel, MD, Nadine Odo, BA, CCRC , \\ Taylor Glenn MD and Vaibhav Bora, MD
}

\author{
${ }^{1}$ Assistant Professor, Anesthesiology and Perioperative Medicine, Augusta University, USA \\ ${ }^{2}$ Pharmacist, Department of Pharmacy, Augusta University, USA \\ ${ }^{3}$ Associate Professor, Cardiothoracic Surgery, Augusta University, USA \\ ${ }^{4}$ Research Associate, Anesthesiology and Perioperative Medicine, Augusta University, USA \\ ${ }^{5}$ Anesthesiology Resident, Intermountain Healthcare, Murray, Utah, USA \\ ${ }^{6}$ Assistant Professor, Cleveland Medical Center, Case Western Reserve University, USA
}

*Corresponding author: Mohamed Ben-Omran, MD, Assistant Professor of Anesthesiology and Critical Care Medicine, Department of Anesthesiology and Perioperative Medicine, Augusta University, 1120 15 th St. BI-2144, Augusta, GA, 30912, USA, Tel: 6179538493; 7067210091, Fax: 706-721-7763

\begin{abstract}
Vasoplegic syndrome is a vasodilatory shock characterized by significant hypotension, normal or high cardiac output, and increased requirement for intravenous fluid resuscitation and vasopressors. It is a relatively common complication following cardiac surgery. We describe the case of a 77-year-old man who developed prolonged vasoplegic syndrome which was refractory to high doses of conventional vasopressors following coronary artery bypass graft surgery. Given the possible increased risk of serotonin syndrome associated with concurrent administration of methylene blue and tramadol, we elected not to administer methylene blue in favor of hydroxocobalamin due to its favorable adverse effect profile. A high dose of intravenous hydroxocobalamin was administered as a rescue agent in the treatment of vasoplegic syndrome. The patient's mean arterial blood pressure (MAP) increased. The vasopressors dosages were markedly reduced within the first hour and subsequently discontinued within 18 hours. Hydroxocobalamin was advocated for this patient as a safer alternative to methylene blue in the setting of concomitant serotonergic drug use to avoid serotonin syndrome.
\end{abstract}

\section{Keywords}

Hydroxocobalamin, Vitamin B12, Vasoplegia, Vesoplegic syndrome, Cardiac surgery, Serotonin toxicity, Serotonin syndrome, Methylene blue

\section{Glossary of Terms}

ACEI: Angiotensin-Converting Enzyme Inhibitors; ARB: Angiotensin II Receptor Blocker; Cl: Cardiac Index; ICU: Intensive Care Unit; IL: Interleukin; LAD: Left Anterior Descending Coronary Artery; MAP: Mean Arterial Pressure; NO: Nitric Oxide; SVG: Saphenous Vein Graft; SVR: Systemic Vascular Resistance

\section{Introduction}

Vasoplegia is a well-recognized complication following cardiac surgery. It is a relatively common syndrome, with an incidence of $5-45 \%$. The lowest and highest incidence are related to off-pump procedures and patients with orthotopic heart transplantation, respectively $[1,2]$. As a vasodilatory shock, it is characterized by significant hypotension with a mean arterial pressure (MAP) $<50 \mathrm{mmHg}$, reduced systemic vascular resistance (SVR $<800$ dynes-s $/ \mathrm{cm}^{5}$ ), in a normal or high cardiac output setting (cardiac index $[\mathrm{Cl}]>2.2 \mathrm{~L} /$ $\mathrm{min} / \mathrm{m}^{2}$ ), normal or decreased filling pressures, and increased requirement for intravenous fluid resuscitation and vasopressors [3]. It is associated with increased intensive care unit (ICU) and hospital stays and increased morbidity and mortality secondary to multiorgan dys-

Citation: Ben-Omran M, Huang E, Patel VS, Odo N, Glenn T, et al. (2021) High-Dose Intravenous Hydroxocobalamin for Persistent Vasoplegic Syndrome after Cardiac Surgery. Clin Med Rev Case Rep 8:335. doi.org/10.23937/2378-3656/1410335

Accepted: January 28, 2021: Published: January 30, 2021

Copyright: (c) 2021 Ben-Omran M, et al. This is an open-access article distributed under the terms of the Creative Commons Attribution License, which permits unrestricted use, distribution, and reproduction in any medium, provided the original author and source are credited. 
function. Persistent refractory vasoplegia of $>36$ hours has a mortality rate as high as $25 \%$ [4].

Here, we report the successful administration of a high dose of intravenous hydroxocobalamin as a rescue agent to manage persistent refractory vasoplegic syndrome following cardiopulmonary bypass surgery. Written HIPAA authorization and written informed consent were obtained from the patient who agreed to have his anonymized clinical information published in this article.

\section{Case Description}

A 77-year-old man presented to the emergency department with a complaint of an episode of dizziness and lightheadedness. His medical history was significant for coronary artery disease, hypertension, hyperlipidemia, and chronic back pain. His medications included atenolol, amlodipine, simvastatin, and tramadol. A 12lead electrocardiogram revealed bigeminy. The patient was admitted for a cardiac workup. Results of the cardiac stress test suggested ischemic changes. The left heart catheterization revealed multivessel coronary artery disease (MVCAD) with $95 \%$ occlusion of the distal left main and left anterior descending (LAD), coronary artery, 70\% occlusion of the obtuse marginal (OM), and $80 \%$ occlusion of distal right coronary artery (RCA). The left ventricular ejection fraction (LVEF) was preserved (60\%).

The patient thrice underwent coronary artery bypass grafting: Left internal mammary artery to LAD, saphenous vein graft (SVG) to the distal posterior descending artery, and SVG to obtuse marginal artery. Total cardiopulmonary pump time was 75 minutes. There were no intra-operative complications. The patient was sedated and intubated while being transported to the ICU, where he was extubated within a few hours of admission. The patient remained A-paced at $90 \mathrm{bpm}$ and required a small dose of norepinephrine $(0.02-0.03 \mathrm{mcg} /$ $\mathrm{kg} / \mathrm{min}$ ) to maintain a goal MAP of $>65 \mathrm{mmHg}$; $\mathrm{Cl}$ remained above $2 \mathrm{~L} / \mathrm{m}^{2}$.

On postoperative day 1 , the patient continued to require higher dosages $(0.05-0.08 \mathrm{mcg} / \mathrm{kg} / \mathrm{min})$ of norepinephrine infusion. Pulmonary artery catheter parameters indicated vasoplegia, which was unresponsive to multiple fluid boluses challenges. That was further complicated by a short episode of atrial fibrillation with a rapid ventricular response that converted back to sinus rhythm after a $150 \mathrm{mg}$ bolus dose of intravenous amiodarone. Despite this conversion, the patient's hemodynamic status continued to worsen, urine output decreased, and norepinephrine requirement increased to $0.25 \mathrm{mcg} / \mathrm{kg} / \mathrm{min}$, which necessitated the addition of vasopressin at a dose of $0.04 \mathrm{U} / \mathrm{min}$. Two doses (12 hours apart) of $100 \mathrm{mg}$ intravenous hydrocortisone were administrated, however, his hemodynamics status showed limited improvement, and vasopressors requirements remained high.
Persistent vasoplegia remained at the top of the differential diagnosis as the patient's clinical course progressed. Other possible causes of shock including pulmonary embolism and infection were evaluated. Transthoracic echocardiology was negative for pericardial effusion and regional wall motion abnormalities. Right ventricular function was normal without strain or dilatation, and no gross valvular or ascending aortic pathologies were noted. No clinical or laboratory findings were suggestive of sepsis.

The patient's chronic back pain had been controlled with tramadol, which was resumed postoperatively. Given the possible increased risk of serotonin syndrome associated with concurrent administration of methylene blue and tramadol, we favored administration of hydroxocobalamin over methylene blue for refractory vasoplegia. Five grams of intravenous hydroxocobalamin (Cyanokit, Meridian Medical Technologies, Columbia, MD) was administered over 15 minutes as a rescue treatment for refractory vasoplegia. Arterial blood pressure increased to a level sufficient for reducing norepinephrine dosage to half in the first hour, tapering it off within 4 hours, and discontinuing vasopressin within 18 hours. This improvement in hemodynamic status and sustained increase in the MAP enabled the patient to tolerate diuresis, achieving the targeted negative fluid balance and permitting the addition of metoprolol the following day. The patient was transferred to the wardon postoperative day 4 , and to a rehabilitation center after 7 days of hospitalization.

\section{Discussion}

The precise mechanisms that cause vasoplegic syndrome are complex and not fully understood; however, it has been attributed to increased production of several vasodilating mediators such as interleukins (ILs), mainly IL1, IL6, IL8, tumor necrosis factor, and a relative or absolute deficiency of vasopressin, in addition to nitric oxide (NO) dysregulation $[2,5,6]$. Long cardiopulmonary bypass time; blood transfusion; sepsis; use of a ventricular assist device; low ejection fraction (< $35 \%)$; and recent use of angiotensin-converting enzyme inhibitors (ACEI), angiotensin II receptor blockers (ARB), beta-blockers, or calcium channel blockers, have been identified as risk factors for the development of vasoplegic syndrome after cardiac surgery [7-9]. In our patient, the cardiopulmonary bypass time was 75 minutes, the patient received $1 \mathrm{~L}$ of autologous and $290 \mathrm{~mL}$ of cell saver blood, and had not received ACEI or ARBs in the 24 hours prior to surgery.

Alpha-1 adrenoreceptor agonists and vasopressin continue to be the main and the first-line treatment in vasoplegic syndrome; however, their effectiveness is variable. Methylene blue (methylthioninium chloride) has been conventionally considered the rescue agent in the treatment of vasoplegic syndrome refractory to traditional vasopressors. It acts as NO scavenger and 
inhibits guanylate cyclase and reduces the release of cyclic guanosine monophosphate, thereby minimizing its vasorelaxation effect on the smooth muscles of the vessels [10].

As methylene blue is a potent monoamine oxidase inhibitor, it may precipitate potential serious adverse effects; such as central nervous system toxicity. It has been associated with serotonin syndrome when administered concomitantly with serotonin reuptake inhibitors [11]. Serotonin syndrome is a potentially life-threatening condition; caused by high levels of synaptic serotonin and significant for changes in mental status, neuromuscular hyperactivity, and autonomic hyperactivity. Hyperthermia $\left(>38.5^{\circ} \mathrm{C}\right)$, muscle rigidity, and seizure may occur in severe cases. While the Food and Drug Administration in a 2011 safety announcement warned against the use of methylene blue in patients taking serotonergic drugs, it also noted that if an urgent life-threatening treatment with methylene blue is indicated, the availability of alternative interventions should be considered; and the benefit of methylene blue treatment should be weighed against the risk of serotonin toxicity [12]. In our case we elected not to administer methylene blue in favor of hydroxocobalamin due to its favorable adverse effect profile.

Hydroxocobalamin is an intravenous form of vitamin B12 which is approved by the Food and Drug Administration to treat known or suspected cyanide poisoning. The starting dose of hydroxocobalamin in adults is $5 \mathrm{~g}$ administered as an intravenous infusion over 15 minutes. A few case reports and series have demonstrated that the postoperative administration of intravenous hydroxocobalamin can be effective in restoring vascular tone and improving vasoplegia. Successful administration of this treatment for vasoplegia was first reported in 2014 in a patient who developed the syndrome following cardiac surgery requiring cardiac bypass [10]. Later, Burnes, et al. described a case in which hemodynamic status improved after the administration of hydroxocobalamin for the treatment of post-cardiac surgery vasoplegic syndrome resistant to methylene blue treatment [13]. Cai, et al. successfully utilized intravenous hydroxocobalamin intraoperatively during cardiopulmonary bypass for refractory vasoplegia which was unresponsive to methylene blue [14]. Shah and Tang reported a case series in which they administered hydroxocobalamin to 33 patients and recorded a heterogeneous response among their patients [15].

The mechanism of hydroxocobalamin is proposed to be related to NO synthase inhibition, scavenging of NO, in addition to modification of hydrogen sulfide, and the effects of hydrogen sulfide on NO and vascular smooth muscle cell activity $[16,17]$. Unlike methylene blue, hydroxocobalamin has not been shown to increase the risk of serotonin syndrome, although it is more expensive and may cause chromaturia. No current or known contraindications for hydroxocobalamin administration have been reported in the literature, and doses of up to $30 \mathrm{~g}$ in 24 hours have been reported without major side effects $[10,18]$.

To date, no trial has systematically evaluated the use of this compound in vasoplegia; therefore, its use cannot be widely recommended. Nevertheless, this case report highlights hydroxocobalamin as an alternative in cases where methylene blue may be ineffective or contraindicated in the setting of concurrent serotonergic drugs use. Further studies regarding the effectiveness and safety of hydroxocobalamin in treating refractory vasoplegia following cardiac surgery through controlled clinical trials are warranted.

\section{Author Contributions}

Mohamed Ben-Omran, M.D: This author wrote the paper and approved the final manuscript; Ellen Huang, Pharm.D: This author helped in reviewing and editing the manuscript, approved the final manuscript; Vijay S. Patel, M.D: This author helped in reviewing the manuscript, approved the final manuscript; Nadine Odo, B.A., C.C.R.C: This author helped in Editing and formatting the manuscript, approved the final manuscript; Taylor Glenn M.D: This author helped in collecting of patient data, wrote the initial drafting of the case description, approved the final manuscript; Vaibhav Bora, M.D: This author helped in editing and reviewing the discussion, approved the final manuscript.

\section{Conflicts of Interest}

None.

\section{Financial Disclosures}

None.

\section{References}

1. Liu H, Yu L, Yang L, Green MS (2017) Vasoplegic syndrome: An update on perioperative considerations. J Clin Anesth 40: 63-71.

2. Shaefi S, Mittel A, Klick J, Evans A, Ivascu NS, et al. (2018) Vasoplegia after cardiovascular procedures-pathophysiology and targeted therapy. J Cardiothorac Vasc Anesth 32: 1013-1022.

3. Shapeton AD, Mahmood F, Ortoleva JP (2019) Hydroxocobalamin for the treatment of vasoplegia: a review of current literature and considerations for use. J Cardiothorac Vasc Anesth 33: 894-901.

4. Gomes WJ, Carvalho AC, Palma JH, Teles CA, Branco JN, et al. (1998) Vasoplegic syndrome after open heart surgery. J Cardiovasc Surg (Torino) 39: 619-623.

5. Levy B, Fritz C, Tahon E, Jacquot A, Auchet T, et al. (2018) Vasoplegia treatments: the past, the present, and the future. Crit Care 22: 52.

6. Argenziano M, Chen JM, Choudhri AF, Cullinane S, Garfein E, et al. (1998) Management of vasodilatory shock after cardiac surgery: identification of predisposing factors and use of a novel pressor agent. J Thorac Cardiovasc Surg 116: 973-980. 
7. Levin MA, Lin HM, Castillo JG, Adams DH, Reich DL, et al (2009) Early on-cardiopulmonary bypass hypotension and other factors associated with vasoplegic syndrome. Circulation 120: 1664-1671.

8. Patarroyo $M$, Simbaqueba $C$, Shrestha $K$, Starling RC, Smedira N, et al. (2012) Pre-operative risk factors and clinical outcomesassociated with vasoplegia in recipients of orthotopicheart transplantation in the contemporary era. $\mathrm{J}$ Heart Lung Transplant 31: 282-287.

9. Alfirevic A, Xu M, Johnston D, Figueroa P, Koch CG (2011) Transfusion increases the risk for vasoplegia after cardiac operations. Ann Thorac Surg 92: 812-820.

10. Roderique JD, VanDyck K, Holman B, Tang D, Chui B, et al. (2014) The use of high-dose hydroxocobalamin for vasoplegic syndrome. Ann Thorac Surg 97: 1785-1786.

11. Pedavally S, Fugate JE, Rabinstein AA (2014) Serotonin syndrome in the intensive care unit: clinical presentations and precipitating medications. Neurocrit Care 21: 108-137.

12. Locke A (2015) Methylene blue and the risk of serotonin toxicity. APSF Newsletter 30: 1-16.

13. Burnes ML, Boettcher BT, Woehlck HJ, Zundel MT, Iqbal
$Z$, et al. (2017) Hydroxocobalamin as a rescue treatment for refractory vasoplegic syndrome after prolonged cardiopulmonary bypass. J Cardiothorac Vasc Anesth 31: 10121014.

14. Cai Y, Mack A, Ladlie BL, Martin AK (2017) The use of intravenous hydroxocobalamin as a rescue in methylene blue-resistant vasoplegic syndrome in cardiac surgery. Ann Card Anaesth 20: 462-464.

15. Shah PR, Reynolds PS, Pal N, Tang D, McCarthy $H$, et al. (2018) Hydroxocobalamin for the treatment of cardiac surgery-associated vasoplegia: a case series. Can J Anaesth 65: $560-568$

16. Busse LW, Barker N, Petersen C (2020) Vasoplegic syndrome following cardiothoracic surgery-review of pathophysiology and update of treatment options. Crit Care 24: 36.

17. Gerth K, Ehring T, Braendle M, Schelling P (2006) Nitric oxide scavenging by hydroxocobalamin may account for its hemodynamic profile. Clin Toxicol (Phila) 44: 29-36.

18. DesLauriers CA, Burda AM, Wahl M (2006) Hydroxocobalamin as a cyanide antidote. Am J Ther 13: 161-165. 